\title{
NiMn-based Heusler magnetic shape memory alloys: a review
}

\begin{abstract}
:
Research in the field of magnetic shape memory alloys (MSMAs) has increased in recent years due to their great interest in their potential applications in smart devices because the reversible deformations undergone. These applications range from actuators, sensors to a magnetic refrigerator and a micro-energy transducer. The well-known example of these alloys is the Heusler type, which has excellent properties, such as; the metamagnetic properties, the magnetocaloric effect (MCE) and the giant magnetoresistance effect (MR). The characterization of the different structures of this type of material is vital for the understanding of their macroscopic and microscopic behavior. The structures of these Heusler alloys are: a high temperature $\mathrm{L} 2{ }_{1}$ and $\mathrm{B} 2$ austenite and $\mathrm{L} 1_{0}, 10 \mathrm{M}$ and $14 \mathrm{M}$ martensite a low temperature. This paper provides a comprehensive review on the recent progress in the development of magnetostructural transformation and magnetocaloric effect, as well as the shape-memory effect induced by the magnetic field in Ni-Mn-X (X=In, Sn, Sb) and Ni-CoMn-Y (Y= In, Sn, Sb) Heusler-type MSMAs. The possible challenges and remaining issues are briefly discussed.
\end{abstract}

Keywords: Heusler alloys; martensitic transformation; magnetic shape memory alloys; magnetocaloric; metamagnetic alloy. 


\section{Introduction}

In earlier decades, attractive shape memory alloys (MSMAs) with Heusler structure have an increasing interest in technological applications, due to their exceptional properties. These multifunctional properties include: giant magnetoresistance (MR) [1], deformation reversible [2, 3], magnetic transformation [4], and large magnetocaloric effect (MCE) [5, 6] associated, which range from actuators and sensors [7] to magnetic refrigeration $[8,9]$. The primary cause of the deformation of the structure is the austenite-martensite transition experimented by these materials from a high temperature ordered cubic austenite phase to a low temperature tetragonal, orthorhombic or monoclinic martensite phase. The ferromagneticparamagnetic transition is experienced when Curie limit is over passed. This structural and magnetic transition can be produced by different causes: mechanical stress, magnetic field application or temperature change.

Most extensively studied MSMAs are those called Heusler alloys, which have a generic formula $\mathrm{X}_{2} \mathrm{YZ}$ and named after German chemist Friedrich Heusler, who examined a combination of $\mathrm{Cu}, \mathrm{Mn}$ and $\mathrm{Al}$ is ferromagnetic even if this is not the case for the three fundamental components $[10,11]$. The reason for this originates from the special crystallographic structure of the material. The $\mathrm{Cu}_{2} \mathrm{MnAl}$ was the first Heusler compound. This combination demonstrated an austenitic phase at room temperature whose structure was completely decided three decades later by Bradley and Rodgers [12]. They revealed a L $2_{1}$ cubic structure with the space group $\mathrm{Fm}^{-} 3 \mathrm{~m}$ and a lattice parameter $\mathrm{a}=5.949 \AA$ and a unit cell composed by eight copper atoms and four manganese and aluminum atoms. This class of excellent materials includes a broad accumulation of more than 1000 mixes, called Heusler alloys. These are ternary semiconductor or metallic materials with a stoichiometry of the type 1:1:1 (usual called half-Heusler alloys) or 2:1:1 (usual called full-Heusler alloys) [13]. These days, they are as yet a hot research field [14]. 
The full-Heusler alloys have a general stoichiometric formula $\mathrm{X}_{2} \mathrm{YZ}$. The crystal structure is schematically shown in Figure 1(a). The $\mathrm{X}, \mathrm{Y}$ and $\mathrm{Z}$ elements occupy four different fcc (face centered cubic) lattices, which are shifted along the space diagonal. It is referred to as the $\mathrm{L} 2{ }_{1}$ Heusler structure with the space group $\mathrm{Fm}^{-} 3 \mathrm{~m}$. The $\mathrm{X}$ atoms are positioned on the $(0,0,0)$ and the $(1 / 2,1 / 2,1 / 2)$ lattice, whereas, the $Y$ and $Z$ atoms occupy the $(1 / 4,1 / 4,1 / 4)$ and the $(3 / 4,3 / 4,3 / 4)$ lattices, respectively [14]. The most important disordered state is the B2 structure, which is appeared in Figure 1(b). For this situation, the $\mathrm{Y}$ and the $\mathrm{Z}$ lattices are mixed. Therefore, the unit cell can be described as a bcc (body centered cubic) lattice with $\mathrm{X}$ atoms in the corners and $\mathrm{Y}$ and $\mathrm{Z}$ atoms with $50 \%$ occupancy in the middle position [14].

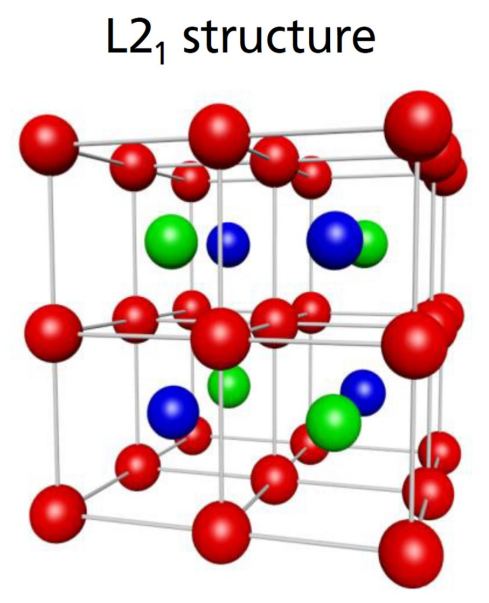

$$
X_{2} Y Z
$$

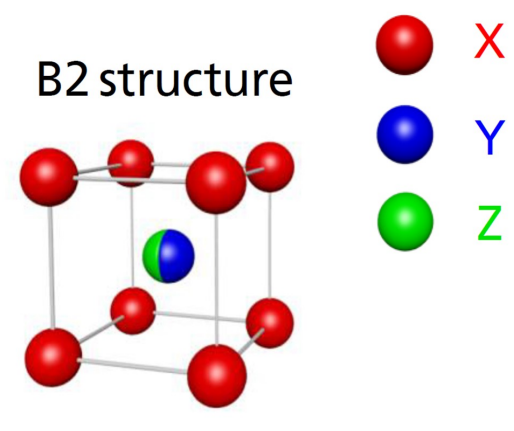

Figure 1: Schematic illustration of the L2 1 and the B2 structure of a Heusler alloy with the chemical composition $\mathrm{X}_{2} \mathrm{YZ}$. The $\mathrm{X}, \mathrm{Y}$ and $\mathrm{Z}$ atoms, which are shown in red, blue and green respectively, occupy different sublattices. Reproduced from reference [14].

The class of magnetic $\mathrm{X}_{2} \mathrm{YZ}$ and $\mathrm{XYZ}$ compounds has multifunctional magnetic properties, such as magneto-optical, semi-metallic ferromagnetic element, magneto-optical effect, shape 
memory effect, topological insulators and magnetocaloric and magneto-structural characteristics [15-19].

Over the years, martensitic transformations (MT) have not been found in full-Heusler alloys, with the exception of $\mathrm{Ni}_{2} \mathrm{MnGa}$ that undergoes an MT and almost no volume change occurs across the transition [20-23]. Today, martensitic transformation is revealed at appropriate off-stoichiometric compositions for any of the $\mathrm{Ni}_{2} \mathrm{MnZ}$ alloys (with $\mathrm{Z}=\mathrm{Ga}$, $\mathrm{Sn}$, In, Sb) $[24,25]$. The differences are that in these alloys (off-stoichiometric), in comparison to stoichiometric one, a volume change occurs across the martensitic transition, depending on what the $\mathrm{Z}$ species [26].
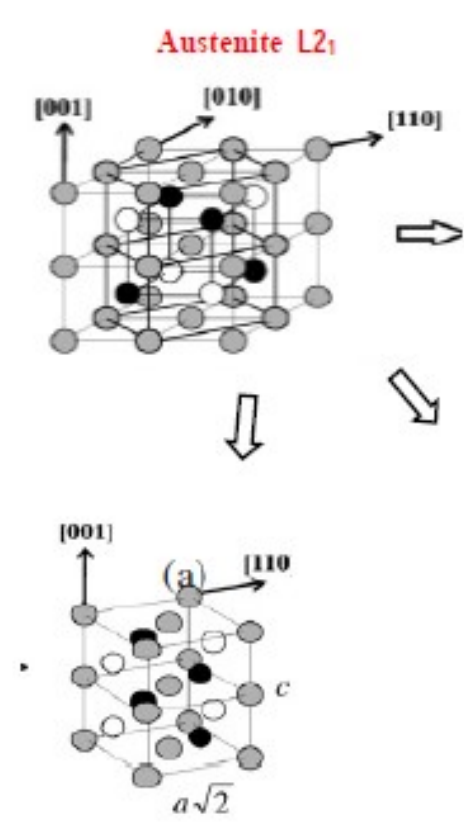

NM

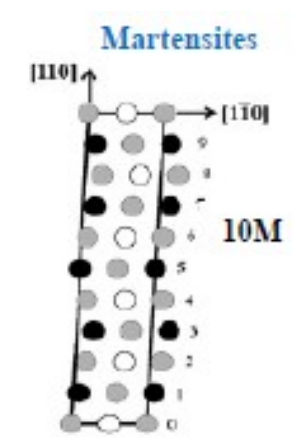

Ni

$\mathrm{OMn}$

- $\mathrm{Ga}$

$14 \mathrm{M}$

Figure 2: Crystal structure of the $\mathrm{Ni}_{50} \mathrm{Mn}_{50-x} \mathrm{Z}_{\mathrm{x}}(\mathrm{Z}=\mathrm{In}, \mathrm{Sn}$ and $\mathrm{Sb}$ ) alloys: (a) structural transition from the phase with a cubic lattice of the L2 1 type into a phase with a tetragonal structure of the $\mathrm{L}_{0}$ type; (b) and (c) lattice distortions in the $10 \mathrm{M}$ and $14 \mathrm{M}$ phases, respectively. Reproduced from reference [26]. 
The most extensively examined Heusler alloys are those based on the $\mathrm{Ni}-\mathrm{Mn}-\mathrm{Ga}$ system [27] and shows the interesting fact that it is the only one exhibiting magnetic properties in its stoichiometric composition, while, other Heusler magnetic alloys only show these properties in off stoichiometry. However, in order to overcome the high cost of Gallium and the generally low martensitic transformation temperature, the search for Ga free alloys has been recently attempted, especially, by presenting different components, for example, In, Sn or Sb. Krenke et al. [28, 29] studied gallium-free Heusler MSMAs replacing Ga for Sn and In. They are reported a full basic investigation of Ni-Mn-Sn [28] and Ni-Mn-In [29].

In this review, we anticipate to give a detailed description of the Ni-Mn-X $(X=I n, S n$, $\mathrm{Sb})$ and Ni-Co-Mn-Y (Y= In, Sn, Sb) systems to better understand this exceptional class of materials. This class of functional materials has potential technological applications in mechanical sensing, energy recovery, magnetic field actuation and magnetic refrigeration [30, 31]. The structure-property relations, and also, the remarkable properties of Heusler alloys are examined in context of various possible applications.

\section{Properties of Ni-Mn-X $(X=I n, S n, S b)$ systems}

Recent researches show that the new Ga-free MSMAs instead of Ni-Mn-Ga system, such as $\mathrm{Ni}-\mathrm{Mn}-\mathrm{X}(\mathrm{X}=\mathrm{In}, \mathrm{Sn}, \mathrm{Sb})$ systems. This is due to the presence of a coupled magnetostructural transition in non-stoichiometric compositions. The magnetostructural transition of these new Heusler alloys is accompanied by a giant inverse magnetocaloric effect and magnetoresistance, as well as by some other interesting properties [5, 6, 26, 30, 31].

\subsection{Structure and phase transformation of Ni-Mn-X $(X=I n, S n, S b)$ systems}

The magnetostructural transition is observed in the Ni-Mn-X (X= In, Sn, Sb) alloys, which is joined by giant magnetoresistance (MR) and large magnetocaloric effect [31-47]. Buchelnikov et al. [31] have demonstrated that $\mathrm{Ni}_{2} \mathrm{Mn}_{1+\mathrm{x}} \mathrm{X}_{1-\mathrm{x}}(\mathrm{X}=\mathrm{In}, \mathrm{Sn}, \mathrm{Sb})$ alloys close to the stoichiometry $(\mathrm{x}=0.3)$ have a cubic structure of type Heusler type L2 $2_{1}$. Hernando et al. 
[32] studied the magnetostructural change in NiMnSn and NiMnIn Heusler alloys. They showed that the alloys were single-phase with ferromagnetic bcc L $2{ }_{1}$ austenite as hightemperature parent phase. At low temperatures austenite changes into a structurally modulated martensite with a lattice symmetry that depends on the system (7M orthorhombic for $\mathrm{Ni}_{50} \mathrm{Mn}_{37} \mathrm{Sn}_{13}, 10 \mathrm{M}$ monoclinic for $\mathrm{Ni}_{50} \mathrm{Mn}_{36} \mathrm{In}_{14}$, and $14 \mathrm{M}$ monoclinic for $\left.\mathrm{Mn}_{50} \mathrm{Ni}_{40} \mathrm{In}_{10}\right)$. Krenke et al. [27] studied the structural change in $\mathrm{Ni}_{0.5} \mathrm{Mn}_{0.5-\mathrm{x}} \mathrm{Sn}_{\mathrm{x}}$ alloys. They showed that the structure of martensite is of type $10 \mathrm{M}, 14 \mathrm{M}$, or $\mathrm{L} 1_{0}$, whereas, that of austenite is of type $\mathrm{L} 2_{1}$, based on the composition Sn. In addition, they are observed that both martensite and austenite are ferromagnetic in $\mathrm{Ni}_{0.5} \mathrm{Mn}_{0.5-\mathrm{x}} \mathrm{Sn}_{\mathrm{x}}$ alloys. For the Heusler $\mathrm{Ni}_{0.5} \mathrm{Mn}_{0.5-\mathrm{x}} \mathrm{In}_{\mathrm{x}}$ alloys, they undergo martensitic transformations in the range of $0.05 \leq x \leq 0.16$, while, in the $0.16 \leq x \leq 0.25$ range, the alloys maintain the cubic phase. When $x=0.16$, the magnetic field-induced structure transformation (MIST) occurs, and martensitic transformation moves $42 \mathrm{~K}$ in the $5 \mathrm{~T}$ field [28]. The structural change in Heusler $\mathrm{Mn}_{50} \mathrm{Ni}_{50-x}(\mathrm{Sn}, \mathrm{In})_{\mathrm{x}}$ shape memory alloys is studied in references [33-35]. They showed that the martensitic transformation (from austenite to modulated monoclinic $14 \mathrm{M}$ martensitic phase) was detected in $\mathrm{Mn}_{50} \mathrm{Ni}_{50-\mathrm{x}} \mathrm{Sn}_{\mathrm{x}}$ and $\mathrm{Mn}_{50} \mathrm{Ni}_{50-\mathrm{x}} \mathrm{In}_{\mathrm{x}}$ samples. Yiwen et al. [39] examined the structural change in $\mathrm{Mn}_{50} \mathrm{Ni}_{50-\mathrm{x}} \mathrm{Sn}_{\mathrm{x}}$ $(x=7-10)$ alloys. The martensite phase is identified to be of $6 \mathrm{M}$ type, whereas, the austenite is with cubic $\mathrm{L} 2{ }_{1}$ structure. When the $\mathrm{Sn}$ content is $7 \%-9 \%$, there is no obvious magnetization difference associated with martensitic transformation, since the martensitic transformation occurs from paramagnetic austenite to weak magnetic martensite. For the ribbons with Sn content of $10 \%$, the martensitic transformation occurs from ferromagnetic austenite to weak magnetic martensite. The Heusler $\mathrm{Ni}_{50} \mathrm{Mn}_{25+} \mathrm{Sb}_{25-\mathrm{x}}$ alloys, have a martensitic phase transitions above $150 \mathrm{~K}$, with $7<\mathrm{x} \leq 10$. The martensitic phases are of orthorhombic structure (space group: Pmm2) in alloys with $13 \leq x \leq 14$, whereas, the austenitic phases show a cubic L $2{ }_{1}$ structure in alloys with $0 \leq \mathrm{x} \leq 12.5$. As the concentration of Mn increases, the transformation 
martensitic increases rapidly, while, the Curie Temperatures of the austenitic phases decrease linearly with increasing $\mathrm{x}$ and change from $370 \mathrm{~K}$ for $(\mathrm{x}=0)$ to $340 \mathrm{~K}$ for $(\mathrm{x}=12.5)$ [40].

Which of such structures stabilize in the martensitic phase of Ni-Mn-X alloys depends on the composition. In Figure 3 is shown the phase diagrams of Ni-Mn-based Heusler alloys. In these phase diagrams, the magnetic and martensitic phase transition temperatures are plotted as a function of the valence electron concentration (e/a) for Ni-Mn-Ga, $\mathrm{Ni}_{50} \mathrm{Mn}_{50-\mathrm{x}} \mathrm{In}_{\mathrm{x}}$, $\mathrm{Ni}_{50} \mathrm{Mn}_{50-\mathrm{x}} \mathrm{Sn}_{\mathrm{x}}$ and $\mathrm{Ni}_{50} \mathrm{Mn}_{50-\mathrm{x}} \mathrm{Sb}_{\mathrm{x}}$ alloys [23]. The ferromagnetic (FM) Curie temperatures of the austenitic and martensitic states are given as $T_{\mathrm{A}}{ }^{\mathrm{C}}$ and $T_{\mathrm{M}}{ }^{\mathrm{C}}$, respectively, and the martensite start temperature is given as $\mathrm{M}_{\mathrm{s}}$. In Figure $3(\mathrm{a}-\mathrm{c})$, it can be observed that at room temperature structure evolves essentially as cubic $\rightarrow 10 \mathrm{M} \rightarrow 14 \mathrm{M} \rightarrow \mathrm{L} 1_{0}$ with increasing $(e / a)$. But in Figure 3 (d), the alloy follows the next sequence cubic $\rightarrow 4 \mathrm{O}-7$ fold (mixture) $\rightarrow L 1_{0}$. The $4 \mathrm{O}$ modulated structure is also observed, for Sn alloy [23].

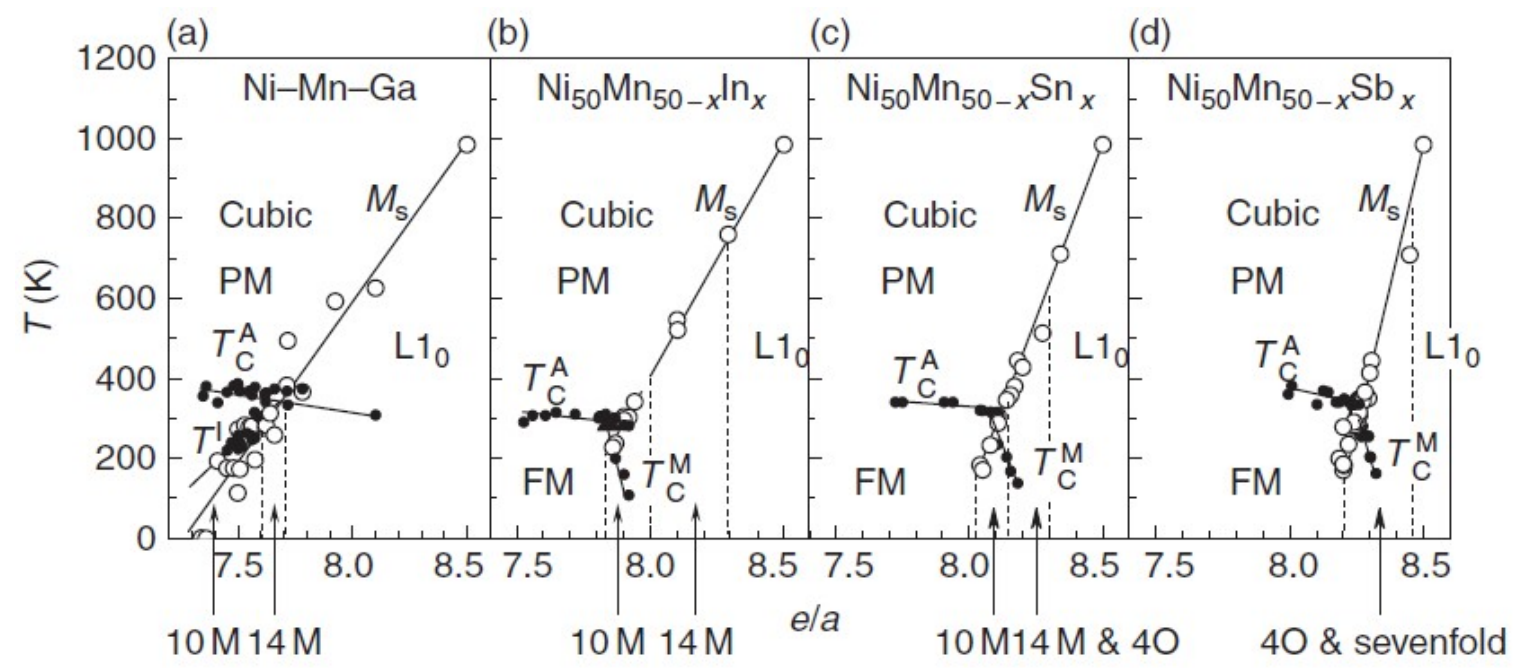

Figure 3: The magnetic and structural phase diagram of Heusler Ni-Mn-X alloys with $\mathrm{X}$ as (a) Ga, (b) In, (c) Sn and (d) Sb. The regions corresponding to the different structures are separated by dashed lines. Reproduced from reference [23].

The width of the compositional areas relies upon the $\mathrm{X}$ species. In the phase diagram, the magnetic and structural transitions depending on the composition of the alloy are portrayed. It is also found that crystalline structure of the martensite depends on processing 
conditions, for example, Santos et al. [41] observed a seven layered orthorhombic martensite, $14 \mathrm{M}$, in $\mathrm{Ni}_{50} \mathrm{Mn}_{37} \mathrm{Sn}_{13}$ with melt spinning technique, whereas, Muthu et al. [42] found a $4 \mathrm{O}$ four layered orthorhombic layered martensite, in the conventional arc melted ingot $\mathrm{Ni}_{50} \mathrm{Mn}_{37} \mathrm{Sn}_{13}$. Hernando et al. reported a modulated $14 \mathrm{M}$ orthorhombic martensite for $\mathrm{Ni}_{50} \mathrm{Mn}_{37} \mathrm{Sn}_{13}$ ribbons and a modulated $10 \mathrm{M}$ orthorhombic martensite for $\mathrm{Ni}_{50} \mathrm{Mn}_{37} \mathrm{Sn}_{13}$ ingots [32].

\subsection{Magnetoresistance and magnetocaloric effect of Ni-Mn-X $(X=I n, S n, S b)$ systems}

The presence of the attractive magnetic exchange interaction between the austenitic and martensitic phases in the Ni-Mn-X $(X=I n, S n, S b)$ alloys results in the appearance of magnetization jumps, which manifest themselves in the possible occurrence of the magnetostructural transition and inverse MCE. Krenke et al. [43] studied for the first time the inverse MCE in alloys $\mathrm{Ni}_{50} \mathrm{Mn}_{35} \mathrm{Sn}_{15}$ and $\mathrm{Ni}_{50} \mathrm{Mn}_{37} \mathrm{Sn}_{13}$. The measurements $\Delta \mathrm{S}_{\mathrm{M}}$ were performed and based on the Maxwell relation. The maximum variation of the entropy is equal to $\sim 15 \mathrm{~J} \cdot \mathrm{kg}^{-1} \cdot \mathrm{K}^{-1}$ at $\mathrm{T}_{\mathrm{m}}=185 \mathrm{~K}$ for the $\mathrm{Ni}_{50} \mathrm{Mn}_{35} \mathrm{Sn}_{15}$ alloy and for the $\mathrm{Ni}_{50} \mathrm{Mn}_{37} \mathrm{Sn}_{13}$ alloy was $\sim 20 \mathrm{~J} \cdot \mathrm{kg}^{-1} \cdot \mathrm{K}^{-1}$ at $\mathrm{T}_{\mathrm{m}}=305 \mathrm{~K}$, upon the change in the magnetic field $\Delta \mathrm{H}=5 \mathrm{~T}$. Ghosh et al. [44] investigated the magnetostructural transformation and magnetocaloric properties of Mnrich $\mathrm{Mn}_{50.5-x} \mathrm{Ni}_{41} \mathrm{Sn}_{8.5+x}(\mathrm{x}=0,1$ and 2$)$ alloys. They showed that the magnetic entropy change $\left(\Delta \mathrm{S}_{\mathrm{M}}\right) \sim 11.85 \mathrm{~J} \cdot \mathrm{kg}^{-1} \cdot \mathrm{K}^{-1}$ was obtained for $\mathrm{x}=0$ at $270 \mathrm{~K}$ due to a change in magnetic field $\Delta \mathrm{H}$ of only $1.5 \mathrm{~T}$. They showed that integrating hysteresis losses, the net refrigerant capacity was estimated to be $-44.82{\mathrm{~J} . \mathrm{kg}^{-1}}^{-1}$ for the same sample, which was found to be larger than that of other Ni-rich Ni-Mn-Sn alloys. This causes a magnetoresistance nearly 33\% to be obtained for these alloys in the presence of $8 \mathrm{~T}$ field differences. Caballero-Flores et al. [45] studied the thermomagnetic properties and magnetocaloric effect in $\mathrm{Ni}_{50.3} \mathrm{Mn}_{36.5} \mathrm{Sn}_{13.2}$ Heusler alloy ribbons. They showed that the maximum value $\Delta \mathrm{S}_{\mathrm{pk}}=17.3 \mathrm{~J} \cdot \mathrm{K}^{-1} \cdot \mathrm{kg}^{-1}$ for an applied magnetics field of $3 \mathrm{~T}$. The inverse magnetocaloric effect (IMCE) of bulk $\mathrm{Ni}_{2+x} \mathrm{Mn}_{1.4-x} \mathrm{Sn}_{0.6}(x=0,0.06$, 
$0.12,0.18$ ) Heusler alloys is researched by Ray et al. [46]. They demonstrated that the change in magnetic entropy initially expanded with excess Ni concentration up to $\mathrm{x}=0.12$ but, then a drastic fall in value is observed for the sample $\mathrm{x}=0.18$ but, the relative cooling power $(\mathrm{RCP})$ value is increased continuously with the excess Ni concentration.

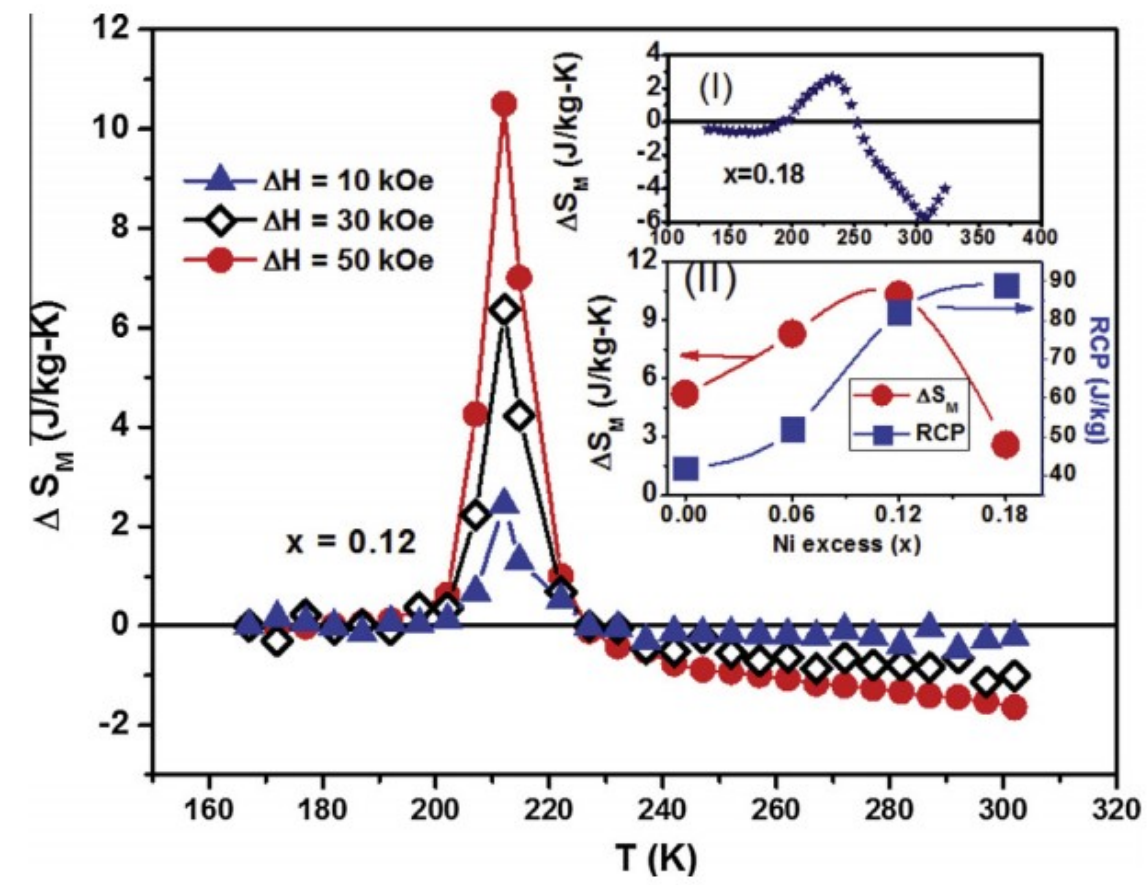

Figure 4: Temperature variation of $\Delta \mathrm{S}_{\mathrm{M}}$ for $\mathrm{x}=0.12$ sample and (I) is showing variation of $\Delta \mathrm{S}_{\mathrm{M}}$ for $\mathrm{x}=0.18$ sample and (II) variation of $\Delta \mathrm{S}_{\mathrm{M}}$ and $\mathrm{RCP}$ value with the excess $\mathrm{Ni}$ concentration. Reproduced from reference [46].

The work made by Buchelnikov et al. [24] demonstrates that the most extreme isothermal attractive entropy change of in $\mathrm{Ni}_{50} \mathrm{Mn}_{35} \mathrm{In}_{15}$ alloy is $\Delta \mathrm{S}_{\mathrm{m}}=35.8 \mathrm{~J} \mathrm{~kg}^{-1} \cdot \mathrm{K}^{-1}$ in the martensitic transition region $(T=311 \mathrm{~K})$ at a change of magnetic field of $\Delta H=5 \mathrm{~T}$, while the isothermal change in the magnetic part of the entropy $\left(\Delta \mathrm{S}_{\mathrm{m}}\right)$ is equal to $\sim 15$ for the $\mathrm{Ni}_{50} \mathrm{Mn}_{35} \mathrm{Sn}_{15}$ alloy and $20 \mathrm{~J} \cdot \mathrm{kg}^{-1} \cdot \mathrm{K}^{-1}$ for $\mathrm{Ni}_{50} \mathrm{Mn}_{37} \mathrm{Sn}_{13}$ alloy, at field change magnetic de $\Delta \mathrm{H}=5 \mathrm{~T}$. Stern-Taulats et al. [47] studied MCE at room temperature in a low hysteresis $\mathrm{Ni}_{51} \mathrm{Mn}_{33.4} \mathrm{In}_{15.6}$ metamagnetic shape-memory alloy (Figure 5). The maximum variation of entropy is $\Delta \mathrm{S}_{\mathrm{m}}=15 \mathrm{~J} \cdot \mathrm{kg}^{-1} \cdot \mathrm{K}^{-1}$ in the martensitic transition region $\left(\mathrm{T}_{\mathrm{m}}=304 \mathrm{~K}\right)$ under the 
variation of the magnetic field $\Delta \mathrm{H}=5 \mathrm{~T}$. Note that the magnetocaloric effect is inverse, which is consistent with the fact that transition temperatures shift to lower values under an applied magnetic field.

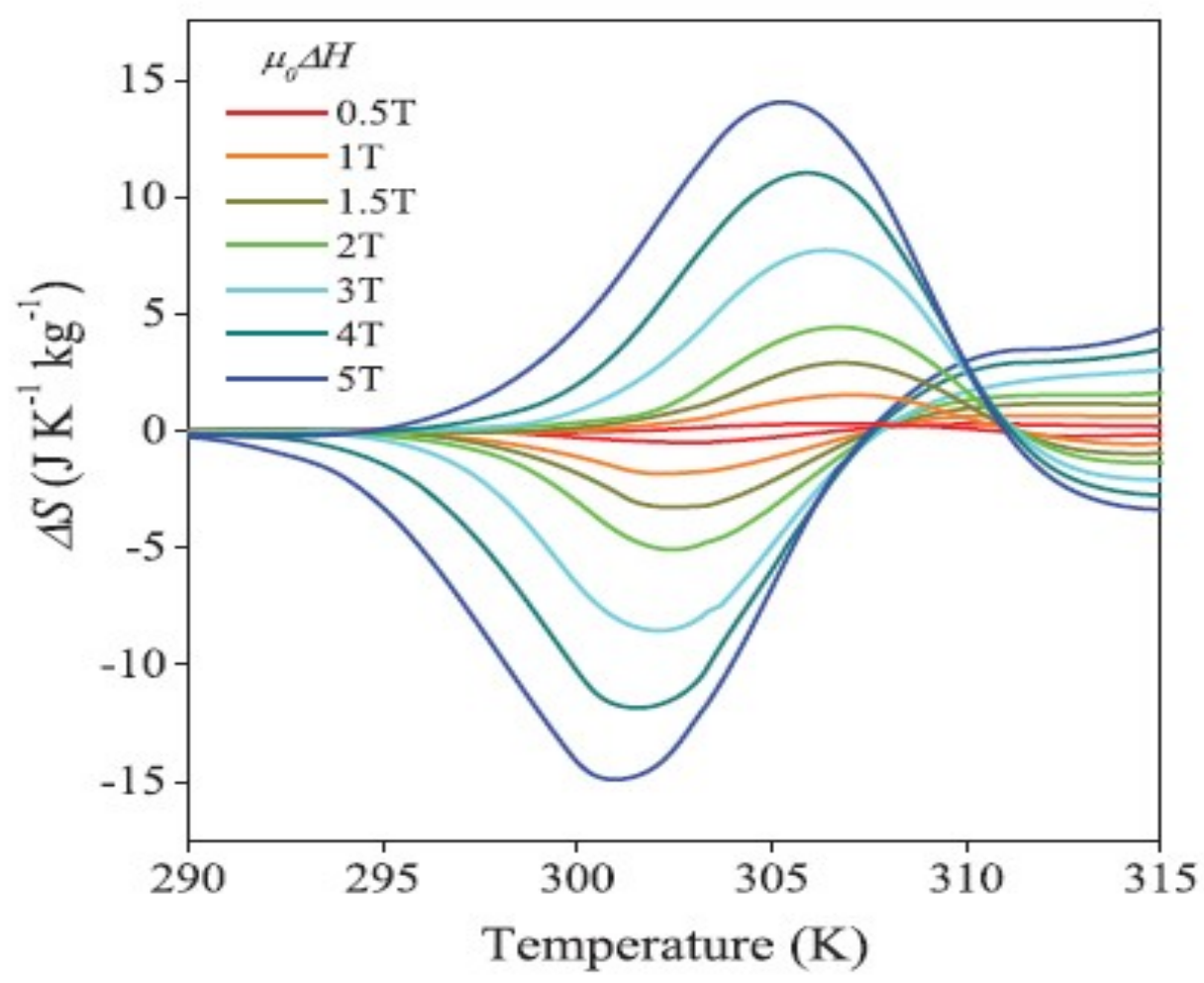

Figure 5: Field-induced entropy changes at selected values of the applied/removed magnetic field from magnetization measurements. Reproduced from reference [47].

Khan et al. [48] investigated the inverse magnetocaloric effect in ferromagnetic $\mathrm{Ni}_{50} \mathrm{Mn}_{(37+x)} \mathrm{Sb}_{(13-x)}$ Heusler alloys and observed the greatest magnitude of the inverse MCE. The maximum value of $\Delta \mathrm{S}_{\mathrm{m}}$ is $20 \mathrm{~J} \cdot \mathrm{kg}^{-1} \cdot \mathrm{K}^{-1}$ in $\mathrm{Ni}_{50} \mathrm{Mn}_{38} \mathrm{Sb}_{12}$ at $297 \mathrm{~K}$ for a magnetic field change of $5 \mathrm{~T}$ as compared to the concentrations $\mathrm{x}=0.5\left(\Delta \mathrm{S}_{\mathrm{m}}\left(\mathrm{T}_{\mathrm{m}}=284 \mathrm{~K}\right)=15.0 \mathrm{~J} \cdot \mathrm{kg}^{-1} \cdot \mathrm{K}^{-1}\right)$ and $\mathrm{x}=0\left(\Delta \mathrm{S}_{\mathrm{m}}\left(\mathrm{T}_{\mathrm{m}}=273 \mathrm{~K}\right)=18.2 \mathrm{~J} \cdot \mathrm{kg}^{-1} \cdot \mathrm{K}^{-1}\right)$. The experimental studies of magnetocaloric effect in $\mathrm{Ni}_{50-\mathrm{x}} \mathrm{Mn}_{38+} \mathrm{Sb}_{12}$ alloys with $\mathrm{x}=-1,0,1$, and 2 performed by Feng et al. [49] (Figure 6). A large reversible negative $\Delta \mathrm{S}_{\mathrm{m}}$ above room temperature was observed. The maximum value of $\Delta \mathrm{S}_{\mathrm{m}}$ is $5.21 \mathrm{~J} . \mathrm{kg}^{-1} \cdot \mathrm{K}^{-1}$ in $\mathrm{Ni}_{49} \mathrm{Mn}_{39} \mathrm{Sb}_{12}$ at $347 \mathrm{~K}$ for a magnetic field change of $5 \mathrm{~T}$. 


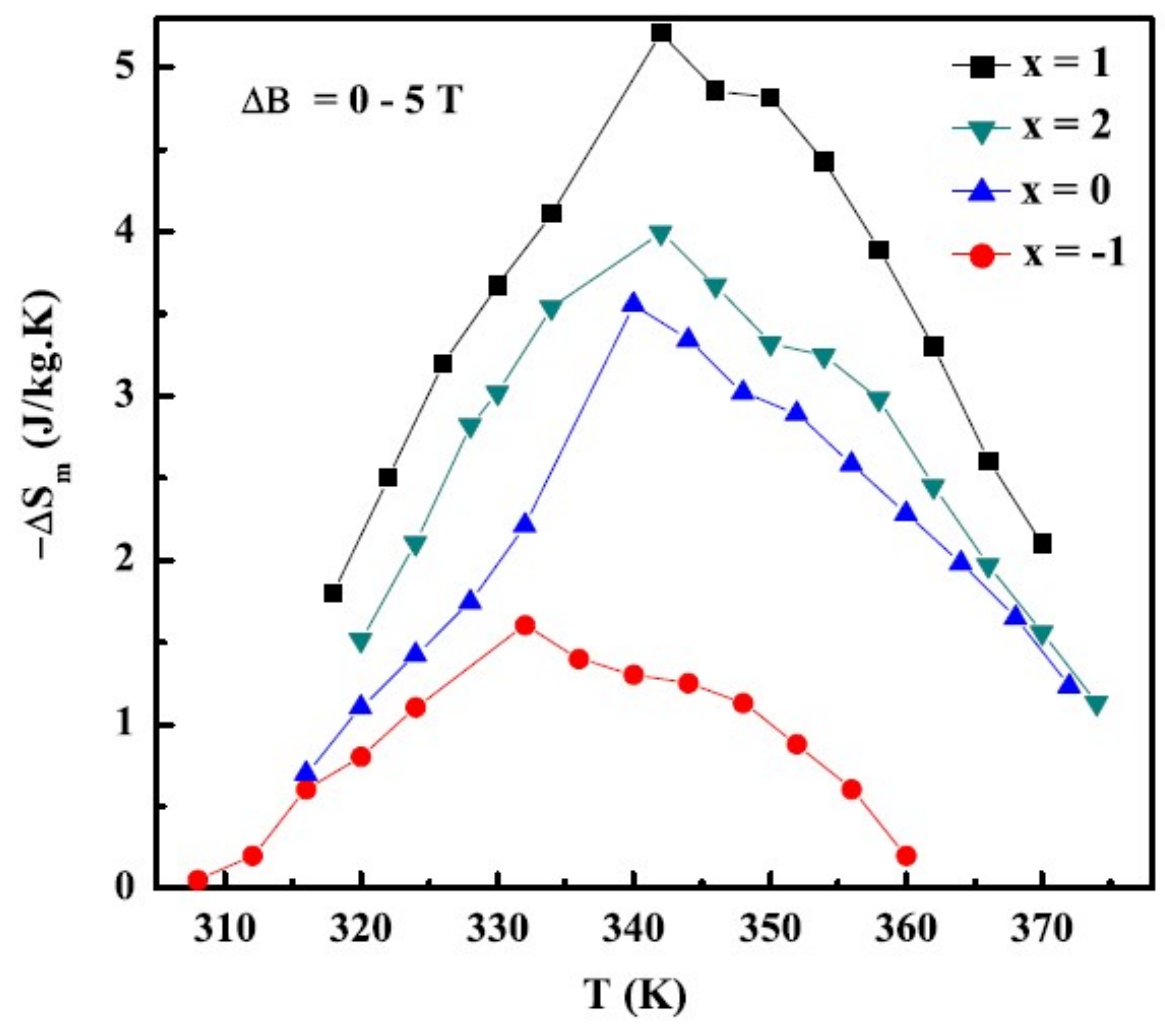

Figure 6: Temperature dependences of the magnetic entropy change in the $\mathrm{Ni}_{50-x} \mathrm{Mn}_{38+x} \mathrm{Sb}_{12}$ alloys with $\mathrm{x}=-1,0,1$ and 2, respectively, for a magnetic-field change from 0 to $5 \mathrm{~T}$.

Reproduced from reference [49].

The alloying of Ni-Mn-X alloys ( $\mathrm{X}=\mathrm{In}, \mathrm{Sn}, \mathrm{Sb})$ with Co leads to a substantial effect in the magnetic properties, in particular, on the behavior of the magnetization. The Cobalt concentration also significantly affects the magnetocaloric properties of these alloys.

\section{Properties of Ni-Co-Mn-Y (Y= In, Sn, Sb) systems}

In Ni-Mn-X alloys, the magnetic coupling between the nearest Mn atoms is probably to be antiferromagnetic, but by doping Co to replace a part of the $\mathrm{Ni}$ atoms, the magnetic coupling of Mn-Mn must be activated for to be ferromagnetic. Therefore, the addition of Co for Ni increases the Curie point, the magnetic moment of the austenitic phase and the change of magnetization at the MT. A prominent behavior of the $\mathrm{Ni}-(\mathrm{Co})-\mathrm{Mn}-\mathrm{X}$ alloys is the possibility of inducing the inverse transformation by a magnetic field and the related 
metamagnetic shape memory effect, i.e. the recovery of a previous strain via field-induced inverse MT.

\subsection{Properties of Ni-Co-Mn-In systems}

Recent studies show that substitution of Nickel by Cobalt in Heusler Ni-Mn-In alloys strongly affects magnetocaloric and magnetic properties. In addition, Co doping will not only improve magnetization of the magnetic phase of Ni-Mn-In, but also improve greatly enhance metamagnetic properties. Expectedly, the extraordinary properties of metamagnetic shape memory effects, the large magnetoresistivity and giant MCE alloys. The Ni-Co-Mn-In alloys have many advantages for the application, such as the composition containing no rare earths or toxic elements, superelastic deformation, high adiabatic temperature change in low field, good oxidation resistance, easy fabrication and high machining [50]. Huang et al. [51] reported that the large reversible $\mathrm{MCE}$ in a $\mathrm{Ni}_{49.8} \mathrm{Co}_{1.2} \mathrm{Mn}_{33.5} \mathrm{In}_{15.5}$ magnetic shape memory alloy was obtained with a seven-layered modulated monoclinic superstructure. And the maximum $\Delta \mathrm{S}_{\mathrm{M}}=14.6 \mathrm{Jkg}^{-1} \cdot \mathrm{K}^{-1}$ a broad operating temperature window of $18 \mathrm{~K}$ under $5 \mathrm{~T}$ were simultaneously achieved. The influence of the atomic order on the martensitic transformation entropy change has studied in a Ni-Mn-In-Co metamagnetic shape memory alloy by Monroe et al. [52]. It is confirmed that the entropy change evolves as a consequence of the variations on the degree of $\mathrm{L} 2{ }_{1}$ atomic order brought by thermal treatments, though, contrary to what occurs in ternary Ni-Mn-In. The entropy change value between around 40 and $5 \mathrm{~J} \cdot{ }^{-1} \mathrm{~kg}^{-1} \cdot \mathrm{K}^{-1}$ can be obtained in a controllable for a single alloy under the appropriate ageing process, which bringing out the possibility of properly tune the magnetocaloric effect. Kainuma et al. [2] studied the magnetic-field-induced shape recovery by reverse phase transformation of $\mathrm{Ni}_{45} \mathrm{Co}_{5} \mathrm{Mn}_{36.6} \mathrm{In}_{13.4}$ alloy. The structure has cubic L2 ${ }_{1}$ structure with $\mathrm{a}=0.5978 \mathrm{~nm}$, and the Curie temperature is $\mathrm{T}_{\mathrm{C}}=382 \mathrm{~K}$. Upon cooling, a martensite phase transformation occurs at a specific temperature TM around RT, accompanied by large magnetization change $(\Delta M)$. For 
the $\mathrm{Ni}_{45} \mathrm{Co}_{5} \mathrm{Mn}_{36.5} \mathrm{In}_{13.5}$ single crystal at 3T [52], when martensitic transformation occurred, the maximum $\Delta \mathrm{M}=115 \mathrm{~mA} \cdot \mathrm{m}^{2} \cdot \mathrm{g}^{-1}$ was obtained. The martensitic structure is a structure modulated at $14 \mathrm{M}$ with $\mathrm{a}=0.4349 \mathrm{~nm}, \mathrm{~b}=0.2811 \mathrm{~nm}, \mathrm{c}=2.998 \mathrm{~nm}$ and $\beta=93.24^{\circ}[2]$. Li et al. [53] reported that the large reversible MCE in a Ni45.3 $\mathrm{Co}_{5.1} \mathrm{Mn}_{36.1} \operatorname{In}_{13.5}$ alloy was obtained with an austenite cubic $\mathrm{L} 2{ }_{1}$ structure. And a large reversible $\Delta \mathrm{S}_{\mathrm{M}}$ above room temperature was observed. The maximum value of $\Delta \mathrm{S}_{\mathrm{M}}$ is $16.7 \mathrm{~J} \cdot \mathrm{kg}^{-1} \cdot \mathrm{K}^{-1}$ for a magnetic field change of $5 \mathrm{~T}$.

Recently, the mechanocaloric effect (including effect barocaloric and elastocaloric effect) and MCE in Heusler Ni-Co-Mn-In alloys, originated from superelasticity or giant volume change on martensite transformation, have increasingly attracting attention [55-57]. Liu et al. [5], reported the inverse MCE during the magnetic field-induced strains (MIST) in $\mathrm{Ni}_{45.2} \mathrm{Co}_{5.1} \mathrm{Mn}_{36.7} \mathrm{In}_{13}$ alloy, the temperature change is important such that $\Delta \mathrm{T}_{\mathrm{ad}}=-6.2 \mathrm{~K}$ at 317 $\mathrm{K}$ in $\Delta \mathrm{H}=1.9$ due to large reverse MCE. Although, the giant $\Delta \mathrm{T}_{\mathrm{ad}}$ is obtained only in the first loading of field, but it sharply decreases after the cycle runs out of the field. Among the factors that cause the reduction of $\Delta \mathrm{T}_{\mathrm{ad}}$, the hysteresis is the main factor in this first-order transition. The irreversible energy loss caused by hysteresis significantly reduces the efficiency in magnetic refrigeration applications.

In Heusler $\mathrm{Ni}_{49.26} \mathrm{Mn}_{36.08} \operatorname{In}_{14.66}$ alloy, an external pressure moves the martensitic transformation temperature $\mathrm{T}_{\mathrm{t}}$ by $2 \mathrm{~K} \mathrm{kbar}^{-1}$ [58], while for the $\mathrm{Ni}_{45.2} \mathrm{Mn}_{36.7} \mathrm{In}_{13} \mathrm{Co}_{5.1}$ alloy this increase of $T_{t}$ is $4.4 \mathrm{~K} \mathrm{kbar}^{-1}$, which is much more pronounced. It is therefore also important to state that inverse MCE materials such as NiMnCoIn demonstrate a conventional barocaloric effect. Magnetic hysteresis is shown in Figure 7. It can be significantly reduced if the sample is magnetized without bias stress but demagnetized under an external pressure. In addition, the theoretical calculations provide that the efficiency of a magnetocaloric material can be improved when it is implemented in a device with a precisely adjustable magnetic field and pressure, compared to a device where only the magnetic field can be varied [59]. 


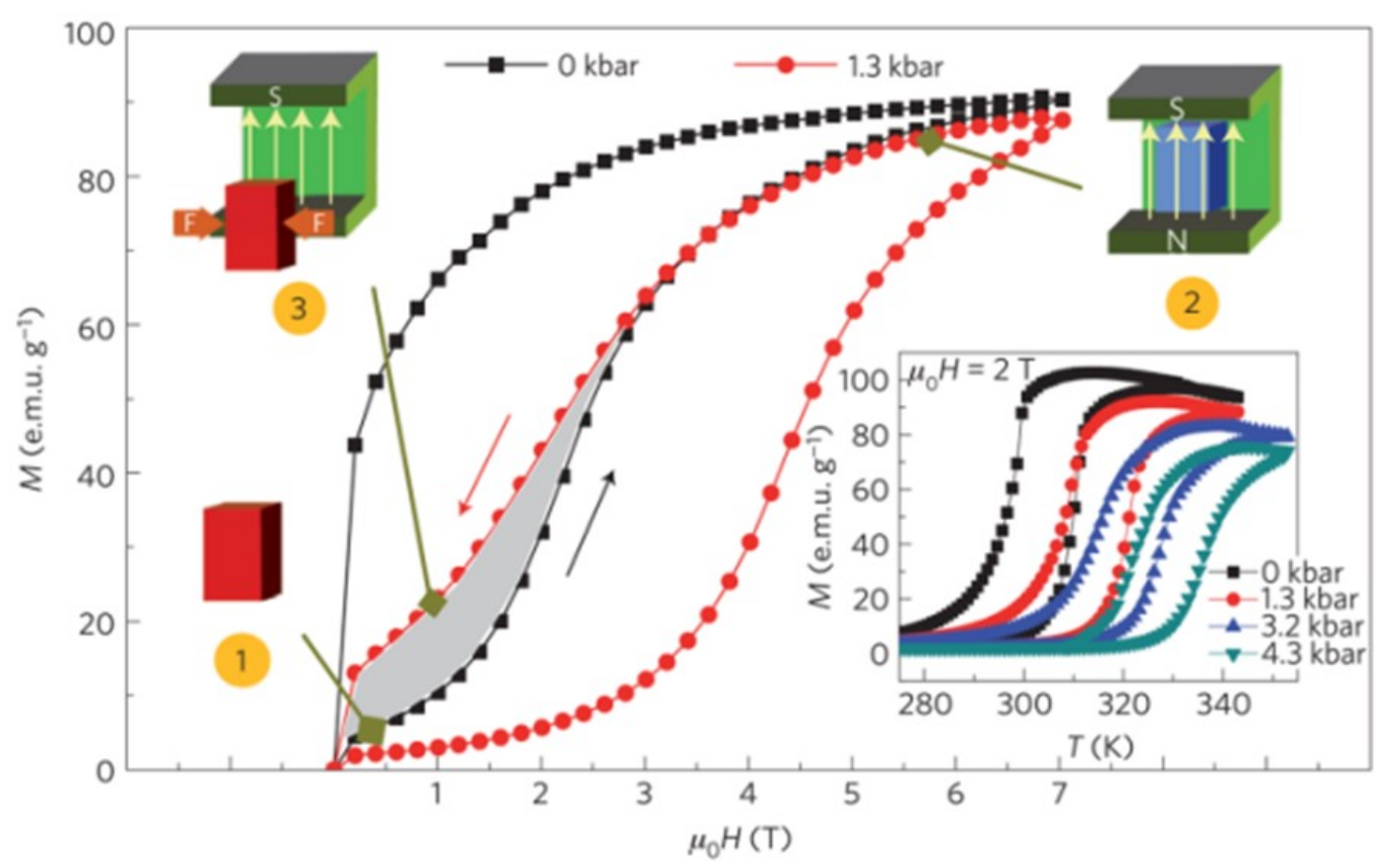

Figure 7: The large thermal irreversibility can be overcome by the combination of applied magnetics and mechanical forces. $\mathrm{M}-\mathrm{T}$ curves under 0 and $1.3 \mathrm{kbar}$ hydrostatic pressure at $308 \mathrm{~K}$ are shown for $\mathrm{Ni}_{45.2} \mathrm{Mn}_{36.7} \mathrm{In}_{13} \mathrm{Co}_{5.1}$. The bottom right corner inset shows the shift of martensitic transition temperatures by the application of a hydrostatic pressure up to $4.3 \mathrm{kbar}$. The forward and reverse transitions can be induced in a relatively low field (with little hysteresis-shaded region in the main figure) when the sample is magnetized in zero pressure but demagnetized under an external pressure. This process is also demonstrated schematically (originally published in [53]).

\subsection{Properties of Ni-Co-Mn-Sn systems}

The Ni-Co-Mn-Sn alloy system is an excellent candidate for magnetic shape memory alloy for practical applications because it contains no expensive components and magnetic elements can be obtained. To gain a deep understanding of the multifunctional properties of these alloys, it is very important to investigate their magnetic properties and structural transformations in detail. Nevertheless, despite several studies that have focused mainly on the influence of Co-addition on the magnetocaloric effect $[60,61]$, there have been few systematic and detailed studies of the composition-dependent magnetostructural transition in 
this system. Deltell et al. [62] studied the structural and thermal behavior of melt-spun alloys of the Ni-Mn-Sn-Co system. They indicated that the martensitic structure consisted of $4 \mathrm{O} 4-$ layer orthorhombic in samples with a higher $\mathrm{Mn} / \mathrm{Sn}$ ratio and $14 \mathrm{M}$ monolayers with 7 modulated layers in samples with a lower $\mathrm{Mn} / \mathrm{Sn}$ ratio. In addition, a change in the martensitic crystalline structure of $14 \mathrm{M}$ to $4 \mathrm{O}$ occurs with the decrease of the martensitic transition temperature. They proposed that the internal stress be induced by the strongly oriented microstructure, which leads to the decrease of the transition temperature due to a refined martensite plate and to the formation of dense martensitic variants of different orientation. In addition, it has also been found that the partial substitution of Ni by Co shifts martensitic transformation to lower temperatures in Ni-Mn-Sn-Co alloys [61].

In a recent study [63], for compositional optimization reasons for MSMEs, the phase diagram of the Ni-Co-Mn-Sn system in the high temperature range was established. However, the phase diagram in the low temperature range has never been explored. The establishment of the complete phase diagram of the Ni-Co-Mn-Sn alloy system is very important for understanding the temperature dependent composition and the functional properties and physical phenomena in this alloy system (Figure 8). 


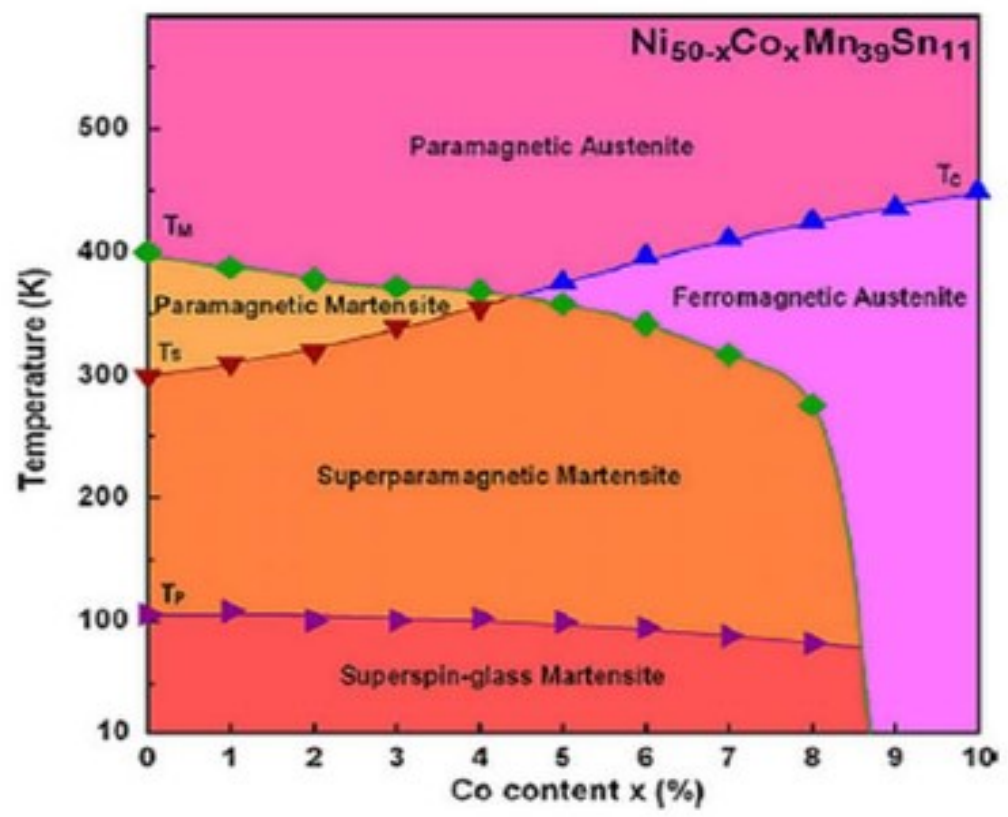

Figure 8: Phase diagrams showing both high- and low-temperature regions of $\mathrm{Ni}_{50-}$ ${ }_{\mathrm{x}} \mathrm{Co}_{\mathrm{x}} \mathrm{Mn}_{39} \mathrm{Sn}_{11}$ quaternary Heusler system. Reproduced from reference [64].

Cong et al. [64] reported that the magnetic properties and both the temperature and magnetic-field-induced structural transformations in the $\mathrm{Ni}_{50-x} \mathrm{Co}_{x} \mathrm{Mn}_{39} \mathrm{Sn}_{11}(0 \leqslant \mathrm{x} \leqslant 10)$ alloys over a large temperature range from $500 \mathrm{~K}$ down to $10 \mathrm{~K}$ was performed. It is revealed that, with increasing $x$, the martensitic transformation temperatures first decrease slowly when $0 \leqslant x \leqslant 4$ and then decrease rapidly when $5 \leqslant x \leqslant 8$; no martensitic transformation was observed in the alloys with $9 \leqslant x \leqslant 10$. Li et al. [65] studied the phase transition and magnetocaloric properties of $\mathrm{Mn}_{50} \mathrm{Ni}_{42-\mathrm{x}} \mathrm{Co}_{\mathrm{x}} \mathrm{Sn}_{8}(0 \leq \mathrm{x} \leq 10)$ alloys. They added that the martensite in alloys possesses the monoclinic crystal structure of type $6 \mathrm{M}$, which austenite to a cubic structure $\mathrm{L} 2{ }_{1}$. In the case of a magnetic field change of $5 \mathrm{~T}$, the magnetic entropy change values $\Delta \mathrm{S}_{\mathrm{M}}$, for the ribbons $\mathrm{Mn}_{50} \mathrm{Ni}_{36} \mathrm{Co}_{6} \mathrm{Sn}_{8}, \mathrm{Mn}_{50} \mathrm{Ni}_{35} \mathrm{Co}_{7} \mathrm{Sn}_{8}$ and $\mathrm{Mn}_{50} \mathrm{Ni}_{34} \mathrm{Co}_{8} \mathrm{Sn}_{8}$ are: $14.1,18.6$ and $16.0 \mathrm{~J} . \mathrm{kg}^{-1} \cdot \mathrm{K}^{-1}$, respectively. Therefore, compared to the Mn-Ni-Sn ternary alloys, the addition of Co allows strong magnetostructural coupling over a wide temperature range with improved magnetocaloric properties in $\mathrm{Mn}_{50} \mathrm{Ni}_{42-\mathrm{x}} \mathrm{Co}_{\mathrm{x}} \mathrm{Sn}_{8}$ alloys. Wang et al. [66] observed a $25 \mathrm{~K}$ increase in the martensitic transition temperature and a corresponding 
important enhancement of the magnetization change $(\Delta \mathrm{M})$ between the martensite and austenite phases in $\left(\mathrm{Ni}_{49} \mathrm{Mn}_{39} \mathrm{Sn}_{12}\right)_{98} \mathrm{Co}_{2}$ alloys obtained by arc melting when contrasted with $\mathrm{Ni}_{49} \mathrm{Mn}_{39} \mathrm{Sn}_{12}$. Moreover, Liu et al. [67] reported that $\Delta \mathrm{M}$ increases dramatically from 0.03 $\mathrm{emu} / \mathrm{g}$ to $50 \mathrm{emu} / \mathrm{g}$ in $\mathrm{Ni}_{45} \mathrm{Co}_{5} \mathrm{Mn}_{37} \mathrm{In}_{13}$ alloys in comparison with $\mathrm{Ni}_{49} \mathrm{Co}_{1} \mathrm{Mn}_{37} \mathrm{In}_{13}$. It was also reported that a decrease in the martensitic transition temperature and an increase in the Curie temperature of martensite $\left(\mathrm{T}_{\mathrm{C}}^{\mathrm{M}}\right)$ and austenite $\left(\mathrm{T}_{\mathrm{C}}{ }^{\mathrm{A}}\right)$ are seen with the addition of cobalt in $\mathrm{Ni}_{44-\mathrm{x}} \mathrm{Co}_{\mathrm{x}} \mathrm{Mn}_{45} \mathrm{Sn}_{11}(\mathrm{x}=0,1,2)$ alloys obtained by arc melting [61].

In contrast to the studies on the MCE in Ni-Co-Mn-Sn alloys, electrical and thermal transports were scarcely investigated. Chen et al. [68] studied the resistivity and thermopower values in zero magnetic fields for $\mathrm{Ni}_{47.5} \mathrm{Co}_{2.5} \mathrm{Mn}_{37} \mathrm{Sn}_{13}$ samples. It is found that the electrical transport is metallic, but in the case of the paramagnetic and ferromagnetic austenite phases, a change of slope occurs at the onset of the ferromagnetic transition.

\subsection{Properties of Ni-Co-Mn-Sb systems}

As already noted, several studies have also reported the magnetostructural properties of the Ni-Mn-Sb system [48, 49]. In order to develop new and better materials belonging to this series and to probe the effect of structural variation on ECM, recent studies have investigated the partial substitution of $\mathrm{Co}$ for $\mathrm{Ni}$ in the non-stoichiometric Ni-Mn-Sb alloy $[69,73]$. Nayak et al. [74] reported the variations in the structural, magnetic and magnetocaloric properties of $\mathrm{Ni}_{50-\mathrm{x}} \mathrm{Co}_{\mathrm{x}} \mathrm{Mn}_{38} \mathrm{Sb}_{12}$ the alloys with $\mathrm{x}=0,2,3,4$ and 5 . They observed a significant improvement in magnetocaloric effect during Co doping in these alloys near room temperature. The value of the magnetic entropy change in $\mathrm{Ni}_{45} \mathrm{Co}_{5} \mathrm{Mn}_{38} \mathrm{Sb}_{12}$ is 29 $\mathrm{J} \cdot \mathrm{kg}^{-1} \cdot \mathrm{K}^{-1}$ at room temperature, whereas this value reaches $34 \mathrm{~J} \cdot \mathrm{kg}^{-1} \cdot \mathrm{K}^{-1}$ at $262 \mathrm{~K}$ under a magnetic field of 5 T. Sahoo et al. [75] compared the magnetic properties, MR, and MCE of as spun ribbon with the annealed ribbon and the bulk alloy of $\mathrm{Ni}_{46} \mathrm{Co}_{4} \mathrm{Mn}_{38} \mathrm{Sb}_{12}$, and observed that TM of as-spun ribbon is higher than that of the bulk sample, while the magnetization of 
as-spun ribbon is lower. $\mathrm{Si}$ substitution for $\mathrm{Sb}$ stabilizes the austenite phase in $\mathrm{Ni}_{46} \mathrm{Co}_{4} \mathrm{Mn}_{38} \mathrm{Sb}_{12-\mathrm{x}} \mathrm{Z}_{\mathrm{x}}(\mathrm{Z}=\mathrm{Si}, \mathrm{Ga})$, whereas $\mathrm{Ga}$ substitution stabilizes the martensite phase. With $\mathrm{x}=1$ for $\mathrm{Si}$, transformation martensitic decreases to $254 \mathrm{~K}$, and a large MCE of $70 \mathrm{J.kg}^{-}$ ${ }^{1} \cdot \mathrm{K}^{-1}$ is acquired [76]. The experimental results in reference [70] reported the magnetic, magnetocaloric and transport properties of $\mathrm{Ni}_{45} \mathrm{Co}_{5} \mathrm{Mn}_{38} \mathrm{Sb}_{12-\mathrm{x}} \mathrm{Ge}_{\mathrm{x}}(\mathrm{x}=0-3)$ alloys. The maximum $\Delta \mathrm{S}_{\mathrm{M}}$ value of $39 \mathrm{~J} \cdot \mathrm{kg}^{-1} \cdot \mathrm{K}^{-1}$ is obtained in the heating mode at $273.5 \mathrm{~K}$ with a field change of $50 \mathrm{kOe}$ fields, whereas, a maximum value of $42 \mathrm{~J} \cdot \mathrm{kg}^{-1} \cdot \mathrm{K}^{-1}$ is obtained in cooling mode at $272.5 \mathrm{~K}$ in the same field. Millan-Solsona et al. [77] studied the polycrystalline Ni$\mathrm{Mn}-\mathrm{Sb}$-Co magnetic shape memory alloys which are known to exhibit a giant inverse magnetocaloric effect. They are reported that the entropy change values associated with the elastocaloric effect. It is shown that uniaxial compressive stresses up to $100 \mathrm{MPa}$ can be applied to the alloys, and the obtained values for the entropy change $\left(\Delta \mathrm{S}=21 \mathrm{~J} \cdot \mathrm{kg}^{-1} \cdot \mathrm{K}^{-1}\right)$ at these stresses compare favorably to $\Delta \mathrm{S}$ values reported for non-magnetic shape memory alloys.

In summary, most of the properties of the quaternary Ni-Co-Mn-Y (Y= In, Sn, Sb) Heusler-type MSMAs outperform those of the Ni-Mn-X (X=In, Sn, Sb) ternary systems.

- The Ni-Co-Mn-In alloy has great metamagnetic properties in which the large magnetization change is $\sim 115 \mathrm{~mA} \cdot \mathrm{m}^{2} \cdot \mathrm{g}^{-1}$ during the martensitic transition. It reveals the largest change in magnetocaloric entropy among quaternary systems.

- The Ni-Co-Mn-Sn alloy has a low thermal hysteresis about $10 \mathrm{~K}$ and a low magnetic hysteresis about $1.5 \mathrm{~T}$.

- The Ni-Co-Mn-Sb alloy shows a high magnetoresistance greater than 70\%.

\section{Conclusion:}

This paper is devoted to a review of experimental investigations on phase transitions and magnetic properties of Heusler Ni-Mn-X (X= In, Sn, Sb) and Ni-Co-Mn-Y (Y= In, Sn, 
Sb) shape memory alloys. Numerous experimental studies have investigated the multifunctional properties of these Heusler alloys. These materials have many excellent properties, such as metamagnetic properties: coincident (ferromagnetic-antiferromagnetic and martensitic transitions), shape memory effect, large magnetocaloric effect and giant magnetoresistance. The nature of high recovery stress, high stress output, high response frequency, and precise control make for a broad perspective in scientific research and engineering applications. However, the study of these alloys has disadvantages such as the fragility of these Heusler type MSMA. The development of Heusler type MSMA is still at the laboratory stage and the scope is limited. New applications, for example in the fields of the magnetic sensor and the actuator, must be explored. In short, basic physics research and Heusler-type MSMA applications are still in the beginning.

\section{References:}

[1] Liu ZH, Liu H, Zhang XX, Zhang XK, Xiao JQ, Zhu ZY, Dai XF, Liu GD, Chen JL, Wu GH. Large negative magnetoresistance in quaternary Heusler alloy $\mathrm{Ni}_{50} \mathrm{Mn}_{8} \mathrm{Fe}_{17} \mathrm{Ga}_{25}$ meltspun ribbons. Appl Phys Lett. 2005;86:182507.

[2] Kainuma R, Imano Y, Ito W, Sutou Y, Morito H, Okamoto S, Kitakami O, Oikawa K, Fujita A, Kanomata T, Ishida K. Magnetic-field-induced shape recovery by reverse phase transformation. Nature. 2006;439:957.

[3] Yu SY, Cao ZX, Ma L, Liu GD, Chen JL, Wu GH, Zhang B, Zhang XX. Realization of magnetic field-induced reversible martensitic transformation in NiCoMnGa alloys. Appl Phys Lett. 2007;91:102507.

[4] Perez-Landazabal JI, Recarte V, Sanchez-Alarcos V, Gomez- Polo C, Cesari E. Magnetic properties of the martensitic phase in Ni-Mn-In-Co metamagnetic shape memory alloys. Appl Phys Lett. 2013;102:101908.

[5] Liu J, Gottschall T, Skokov KP, Moore JD, Gutfleisch O. Giant magnetocaloric effect driven by structural transitions. Nat Mater. 2012;11:620.

[6] Du J, Zheng Q, Ren WJ, Feng WJ, Liu XG, Zhang ZD. Magnetocaloric effect and magnetic-field-induced shape recovery effect at room temperature in ferromagnetic Heusler alloy Ni-Mn-Sb. J Phys D: Appl Phys. 2007;40:5523. 
[7] Marioni MA, O’Handley ROC, Allen SM, Hall SR, Paul DJ, Richard ML. The ferromagnetic shape memory effect in Ni-Mn-Ga. J Mag Mag Mat. 2005;290:35.

[8] Brown GV. Magnetic heat pumping near room temperature. J Appl Phys.1976;47:3673.

[9] Pecharsky VK, Gschneider KA. Magnetic refrigeration. Inter J Refrig.2006;29:1239.

[10] Heusler F, Stark W, Haupt E. Über magnetische manganlegierungen. Verhandlungen der Deutschen Physikalischen Gesellschaft.1903;5.

[11] Heusler F. and Richarz F. Studien über magnetisierbare manganlegierungen. Zeitschrift für Anorganische Chemie.1909;61:265.

[12] Bradley A. J. and Rodgers J. W. The crystal structure of the Heusler alloys. Proceedigs of the Royal Society of London. Series A. Math and Phys Sci.1934;144:340.

[13] Groot RAd, Mueller FM, Engen PGV, Buschow KHJ. New class of materials: halfmetallic ferromagnets. Phys Rev Lett. 1983;50:2024.

[14] Graf T, Felser C, Parkin SSP. Simple rules for the understanding of Heusler compounds. Prog Solid State Chem. 2011;39:1.

[15] Wang CW, Wang JM, Jiang CB. A linear elastic $\mathrm{Ni}_{50} \mathrm{Mn}_{25} \mathrm{Ga}_{9} \mathrm{Cu}_{16}$ martensitic alloy. Rare Met. 2013;32:29.

[16] Trudel S, Gaier O, Hamrle J, Hillebrands B. Magnetic anisotropy, exchange and damping in cobalt-based full-Heusler compounds: an experimental review. J Phys D Appl Phys. 2010;43:193001.

[17] Kreiner G, Kalache A, Hausdorf S, Alijani V, Qian JF, Shan G, Burkhardt U, Ouardi S, Felser C. New Mnz-based Heusler compounds. Z Anorg Allg Chem. 2014;640:738.

[18] Ritchie L, Xiao G, Ji Y, Chen TY, Chien CL, Wu G. Magnetic, structural, and transport properties of the Heusler alloys $\mathrm{Co}_{2} \mathrm{MnSi}$ and NiMnSb. Phys Rev B. 2003;68:104430.

[19] Liu G, Dai X, Liu H, Chen J, Li Y, Xiao G, Wu G. Mn ${ }_{2} \mathrm{CoZ}$ (Z= Al, Ga, In, Si, Ge, Sn, Sb) compounds: structural, electronic, and magnetic properties. Phys Rev B. 2008;77:014424.

[20] Ullakko K, Huang JK, Kantner C, O'Handley RC and Kokorin VV. Large magneticfield-induced strains in $\mathrm{Ni}_{2} \mathrm{MnGa}$ single crystals. Appl Phys Lett.1996; 69:1966.

[21] Ranjan R, Banik S, Barman SR, Kumar U, Mukhopadhyay PK and Pandey D. Powder xray diffraction study of the thermoelastic martensitic transition in $\mathrm{Ni}_{2} \mathrm{Mn}_{1.05} \mathrm{Ga}_{0.95}$. Phys $\mathrm{Rev}$ B.2006;74:224443.

[22] Dikshtein I, Koledov V, Shavrov V, Tulaikova A and Cherechukin A. Phase Transitions in Intermetallic Compounds Ni-Mn-Ga with Shape Memory Effect. 1EEE Trans Magn. 1999; $35: 3811$. 
[23] Acet M, Mañosa L and Planes A. Magnetic-field-induced effects in martensitic Heuslerbased magnetic shape memory alloys. K. H. J. Buschow (Ed.), Handbook of Magnetic Materials.2011;19:231.

[24] Khovaylo VV, Buchelnikov VD, Kainuma R, Koledov VV, Ohtsuka M, Shavrov VG, Takagi T, Taskaev SV and Vasiliev AN. Phase transitions in $\mathrm{Ni}_{2+\mathrm{x}} \mathrm{Mn}_{1+\mathrm{x}} \mathrm{Ga}$ with a high $\mathrm{Ni}$ excess. Phys Rev B.2005; 72:224408.

[25] Aksoy S, Krenke T, Acet M, Wassermann EF, Moya X, Mañosa L and Planes A. Magnetization easy axis in martensitic Heusler alloys estimated by strain measurements under magnetic field. Appl Phys Lett. 2007;91:251915.

[26] Planes A, Mañosa L and Acet M. Magnetocaloric effect and its relation to shape-memory properties in ferromagnetic Heusler alloys. J Phys: Condens Matter.2009;21:233201.

[27] Krenke T, Acet M, Wassermann E, Moya X, Manosa L, Planes A. Martensitic transitions and the nature of ferromagnetism in the austenitic and martensitic states of Ni-Mn-Sn alloys. Phys Rev B. 2005;72:014412.

[28] Krenke T, Acet M, Wassermann E, Moya X, Manosa L, Planes A. Ferromagnetism in the austenitic and martensitic states of Ni-Mn-In alloys. Phys Rev B. 2006;73:174413.

[29] Wang HF, Wang JM, Jiang CB, Xu HB. Phase transition and mechanical properties of $\mathrm{Ni}_{30} \mathrm{Cu}_{20} \mathrm{Mn}_{37+\mathrm{x}} \mathrm{Ga}_{13-\mathrm{x}}(\mathrm{x}=0-4.5)$ alloys. Rare Met. 2014;33:547.

[30] Li Z, Jing C, Zhang HL, Qiao YF, Cao SX, Zhang JC, Sun L. A considerable metamagnetic shape memory effect without any prestrain in $\mathrm{Ni}_{46} \mathrm{Cu}_{4} \mathrm{Mn}_{38} \mathrm{Sn}_{12}$ Heusler alloy. $\mathrm{J}$ Appl Phys. 2009;106:083908.

[31] Buchelnikov VD, Sokolovskiy VV. Magnetocaloric effect in Heusler Ni-Mn-X alloys (X= Ga, In, Sn, Sb). Phys met Matellogr. 2011;112:633.

[32] Hernando B, Sánchez Llamazares JL, Santos JD, Sánchez ML, Escoda L1, Suñol JJ, Varga R, García C, González J. Grain oriented NiMnSn and NiMnIn Heusler alloys ribbons produced by melt spinning: Martensitic transformation and magnetic properties. J Mag Magn Mater. 2009;321:763.

[33] Bachaga T, Rekik H, Krifa M, Sunol JJ, Khitouni M. Investigation of the enthalpy/entropy variation and structure of $\mathrm{Ni}-\mathrm{Mn}-\mathrm{Sn}$ (Co, In) melt-spun alloys. https://doi.org/ 10.1007/s10973-016-5716-z.

[34] Coll R, Saurina J, Escoda L, Sunol JJ. Thermal analysis of $\mathrm{Mn}_{50} \mathrm{Ni}_{50-x}(\mathrm{Sn}, \mathrm{In})_{\mathrm{x}}$ Heusler shape memory alloys. J Therm Anal Calorim. 2018. https://doi.org/10.1007/s10973-0187551-x. 
[35] Bachaga T, Daly R, Escoda L, Sunol JJ, Khitouni M. Influence of chemical composition on martensitic transformation of MnNiIn shape memory alloys. J Therm Anal Calorim. 2015;122:167.

[36] Barandiaran JM, Chernenko VA, Cesari E, Salas D, Lazpita P, Gutierrez J, Orue I. Magnetic influence on the martensitic transformation entropy in Ni-Mn-In metamagnetic alloy. Appl Phys Lett. 2013;102:071904.

[37] González-Legarreta L, Caballero-Flores R, Hernando B, González-Alonso D, Rosa WO, Suñol JJ, González J. Magnetostructural phase transition in off-stoichiometric Ni-MnIn Heusler alloy ribbons with low In content. J Mag Magn Mater.2015;0304:190.

[38] Sutou Y, Imano Y, Koeda N, Omori T, Kainuma R, Ishida K, Oikawa K. Magnetic and martensitic transformations of $\mathrm{NiMnX}(\mathrm{X}=\mathrm{In}, \mathrm{Sn}, \mathrm{Sb})$ ferromagnetic shape memory alloys. Appl Phys Lett. 2004;85:4358.

[39] Yiwen J, Li Z, Li Zh, Yang Y, Yang B, Zhang Y, Esling C, Zhao X, Zuo L. Magnetostructural transformation and magnetocaloric effect in Mn-Ni-Sn melt-spun ribbons. Eur Phys J Plus. 2017;V132:1.

[40] Khan M, Dubenko I, Stadler S, Ali N. Magnetostructural phase transitions in $\mathrm{Ni}_{50} \mathrm{Mn}_{25+\mathrm{x}} \mathrm{Sb}_{25-\mathrm{x}}$ Heusler alloys. J Phys Condens Mat. 2008;20:235204.

[41] Santos JD, Sánchez T, Álvarez P, Sánchez ML, Sánchez ML, Sánchez Llamazares JL, Hernando B. Microstructure and magnetic properties of $\mathrm{Ni}_{50} \mathrm{Mn}_{37} \mathrm{Sn}_{13}$ Heusler alloy ribbons, Appl Phys Lett.2008;103:07B326.

[42] Muthu S, Rama Rao NV, Maniel Raja M, Raj Kumar DM, Mohan Radheep D, Arumugan $\mathrm{S}$. Influence of $\mathrm{Ni} / \mathrm{Mn}$ concentration on the structural, magnetic and magnetocaloric properties in $\mathrm{Ni}_{50-\mathrm{x}} \mathrm{Mn}_{37+\mathrm{x}} \mathrm{Sn}_{13}$ Heusler alloys. J Phys D: Appl Phys. 2010;43: 425002.

[43] Krenke T, Duman E, Acet M, et al. Inverse Magnetocaloric Effect in Ferromagnetic NiMn-Sn Alloys. Nature Mater. 2005;4:450.

[44] Ghosh A, Mandal K. Large magnetic entropy change and magnetoresistance associated with a martensitic transition of Mn-rich $\mathrm{Mn}_{50.5-\mathrm{x}} \mathrm{Ni}_{41} \mathrm{Sn}_{8.5+x}$ alloys. J Phys D: Appl Phys.2013;46:435001.

[45] Caballero-Flores R, González-Legarreta L, Rosa WO, Sánchez T, Prida VM, Escoda L, Suñol JJ, Btdalovd AB, Alievd AM, Koledove VV, Shavrove VG, Hernando B. Magnetocaloric effect, magnetostructural and magnetic phase transformations in $\mathrm{Ni}_{50.3} \mathrm{Mn}_{36.5} \mathrm{Sn}_{13.2}$ Heusler alloy ribbons. J Alloys Compds. 2015;629:332. 
[46] Mayukh K Ray, K Bagani, S Banerjee. Effect of excess Ni on martensitic transition, exchange bias and inverse magnetocaloric effect in $\mathrm{Ni}_{2+x} \mathrm{Mn}_{1.4-x} \mathrm{Sn}_{0.6}$ alloy. J Alloys Compds. 2014;600:55.

[47] Stern-Taulats E, Castillo-Villa PO, Manosa L, Frontera C, Pramanick S, Majumdar S, and Planes A. Magnetocaloric effect in the low hysteresis Ni-Mn-In metamagnetic shapememory Heusler alloy. J Appl Phys. 2014;115:173907.

[48] Khan M, Ali N, and Stadler S. Inverse Magnetocaloric Effect in Ferromagnetic $\mathrm{Ni}_{50} \mathrm{Mn}_{(37+x)} \mathrm{Sb}_{(13-x)}$ Heusler Alloys. J Appl Phys. 2007;101:053919.

[49] Feng WJ, Zhang Q, Zhang LQ, Li B, Du J, Deng YF, Zhang ZD. Large reversible hightemperature magnetocaloric effect in $\mathrm{Ni}_{50-\mathrm{x}} \mathrm{Mn}_{38+\mathrm{x}} \mathrm{Sb}_{12}$ alloys. Sol Stat Com. 2010;150:949.

[50] Liu J, Gottschall T, Skokov KP, Moore JD, Gutfleisch O. Giant magnetocaloric effect driven by structural transitions. Nat Mater. 2012;11:620.

[51] Huang L, Cong D. Y, Ma L, Nie1 ZH, Wang ZL, Suo HL, Ren Y and Wang YD. Large reversible magnetocaloric effect in a Ni-Co-Mn-In magnetic shape memory alloy. Appl Phys Lett. 2016;108:032405.

[52] Monroe JA, Karaman I, Basaran B, Ito W, Umetsu RY, Kainuma R, Koyama K, Chumlyakov YI. Direct measurement of large reversible magnetic-field-induced strain in NiCo-Mn-In metamagnetic shape memory alloys. Acta Mater.2012;60:6883.

[53] Li Zh, Li Z, Yang B, Zhao X, Zuo L. Giant low-field magnetocaloric effect in a textured $\mathrm{Ni}_{45.3} \mathrm{Co}_{5.1} \mathrm{Mn}_{36.1} \operatorname{In}_{13.5}$ alloy. Script Mater.2018;151:61.

[54] Lu B, Xiao F, Yan A, Liu J. Elastocaloric effect in a textured polycrystalline Ni-Mn-InCo metamagnetic shape memory alloy. Appl Phys Lett. 2014;105:161905.

[55] Xu X, Kihara T, Tokunaga M, Matsuo A, Ito W, Umetsu RY, Kindo K, Kainuma R. Magnetic field hysteresis under various sweeping rates for Ni-Co-Mn-In metamagnetic shape memory alloys. Appl Phys Lett. 2013;103:122406.

[56] Emre B, Yuce S, Stern-Taulats E, Planes A, Fabbrici S, Albertini F, Manosa L. Large reversible entropy change at the inverse magnetocaloric effect in Ni-Co-Mn-Ga-In magnetic shape memory alloys. J Appl Phys. 2013;113:213905.

[57] Kihara $\mathrm{T}, \mathrm{Xu} \mathrm{X}$, Ito $\mathrm{W}$, Kainuma $\mathrm{R}$, Tokunaga $\mathrm{M}$. Direct measurements of inverse magnetocaloric effects in metamagnetic shape-memory alloy NiCoMnIn. Phys Rev B. 2014; 90:214409. 
[58] Manosa L, González-Alonso D, Planes A, Bonnot E, Barrio M, Tamarit JL, Aksoy S, Acet M. Giant solid-state barocaloric effect in the Ni-Mn-In magnetic shape-memory alloy. Nat Mater. 2010; 9:478.

[59] De Oliveira N. Entropy change upon magnetic field and pressure variations. Appl Phys Lett. 2007; 90:052501.

[60] Liu HS, Zhang CL, Han ZD, Xuan HC, Wang DH, Du YW. The effect of Co doping on the magnetic entropy changes in $\mathrm{Ni}_{44-\mathrm{x}} \mathrm{Co}_{\mathrm{x}} \mathrm{Mn}_{45} \mathrm{Sn}_{11}$ alloys. J Alloys Compd. 2009;467:27.

[61] Jing C, Li Z, Zhang HL, Chen JP, Qiao YF, Cao SX, Zhang JC. Martensitic transition and inverse magnetocaloric effect in Co doping Ni-Mn-Sn Heusler alloy. Eur Phys J B. 2009; $67: 193$.

[62] Deltell A, Escoda L, Saurina J, Suñol JJ. Martensitic Transformation in Ni-Mn-Sn-Co Heusler Alloys. Metals 2015;5:695.

[63] Cong DY, Roth S, Potschke M, Hurrich C, Schultz L. Phase diagram and composition optimization for magnetic shape memory effect in Ni-Co-Mn-Sn alloys. Appl Phys Lett. 2010;97:021908.

[64] Cong DY, Roth S, Schultz L. Magnetic properties and structural transformations in NiCo-Mn-Sn multifunctional alloys. Acta Mater. 2012;60:5335.

[65] Li Z, Jiang Y, Li Z, Sánchez Valdés CF, Sánchez Llamazares JL, Yang B, Zhang Y, Esling C, Zhao X and Zuo L. Phase transition and magnetocaloric properties of $\mathrm{Mn}_{50} \mathrm{Ni}_{42}-$ ${ }_{\mathrm{x}} \mathrm{Co}_{\mathrm{x}} \mathrm{Sn}_{8}(0 \leq \mathrm{x} \leq 10)$ melt-spun ribbons. IUCrJ. 2018;5:54.

[66] Wang W, Yu J, Zhai Q, Luo Z, Zheng H. Co-doping effect on the martensitic transformation and magnetic properties of $\mathrm{Ni}_{49} \mathrm{Mn}_{39} \mathrm{Sn}_{12}$ alloy. J Magn Magn Mater.2013; 346:103.

[67] Liu J, Scheerbaum N, Hinz D, Gutfleisch O. Magnetostructural transformation in NiMn-In-Co ribbons. Appl Phys Lett. 2008; 92:162509.

[68] Chen X, Naik VB, Mahendiran R, Ramanujan RV. Optimization of Ni-Co-Mn-Sn Heusler alloy composition for near room temperature magnetic cooling. J Alloys Compd. 2015;618:187.

[69] Nayak AK, Suresh KG, and Nigam AK. Observation of enhanced exchange bias behaviour in NiCoMnSb Heusler alloys. J Phys D: Appl Phys. 2009;42:115004.

[70] Nayak AK, Suresh KG, and Nigam AK. Magnetic, electrical and magneto thermal properties in NiCoMnSb Heusler alloys. J Appl Phys. 2010;107:09A927. 
[71] Nayak AK, Suresh KG, and Nigam AK. Correlation between reentrant spin glass behavior and the magnetic order-disorder transition of the martensite phase in Ni-Co-Mn-Sb Heusler alloys. J Phys: Condens Matter.2011;23:416004.

[72] Nayak AK, Suresh KG, and Nigam AK. Anomalous effects of repeated martensitic transitions on the transport, magnetic and thermal properties in Ni-Co-Mn-Sb Heusler alloy. Acta Mater.2011;59:3304.

[73] Nayak AK, Suresh KG, and Nigam AK. Metastability of magneto-structural transition revealed by sweep rate dependence of magnetization in $\mathrm{Ni}_{45} \mathrm{Co}_{5} \mathrm{Mn}_{38} \mathrm{Sb}_{12}$ Heusler alloy. $\mathrm{J}$ Appl Phys. 2011;109:07A906.

[74] Nayak AK, Suresh KG, Nigam AK. Giant inverse magnetocaloric effect near room temperature in Co substituted NiMnSb Heusler alloys. J Phys D Appl Phys. 2009;42: 035009. [75] Sahoo R, Raj Kumar DM, Arvindha Babu D, Suresh K, Nigam G, Manivel AK, Raja M. Effect of annealing on the magnetic, magnetocaloric and magnetoresistance properties of NiCo-Mn-Sb melt spun ribbons. J Magn Magn Mater. 2013;347:95.

[76] Sahoo R, Nayak AK, Suresh KG, Nigam AK. Effect of Si and Ga substitutions on the magnetocaloric properties of $\mathrm{NiCoMnSb}$ quaternary Heusler alloys. J Appl Phys. 2011;109:07A921.

[77] Millan-Solsona R, Stern-Taulats E, Vives E, Planes A, Sharma J, Nayak AK, Suresh KG, and Manosa L. Large entropy change associated with the elastocaloric effect in polycrystalline Ni-Mn-Sb-Co magnetic shape memory alloys. App Phys Lett. 2014;105, 24190. 